\title{
Complications Per and Post Operatory (CPPO) at the Gabriel Toure University Hospital in Bamako
}

\author{
M. Samaké, S. B. Dembélé, S. Konaté, A. Traoré, K. Madiassa, A. Diarra, Z. Saye, B. Tounkara, \\ A. Traoré, I. Abdillahiiltireh, B. T. Dembélé, B. Y. Sidibé, L. Kanté, I. Diakité, Adégné Togo*, \\ G. Diallo
}

Department of Surgery Hospital Gabriel Touré Bamako, Mali

Email: *ap.togo@yahoo.fr

How to cite this paper: Samaké, M., Dembélé, S.B., Konaté, S., Traoré, A., Madiassa, K., Diarra, A., Saye, Z., Tounkara, B., Traoré, A., Abdillahiiltireh, I., Dembélé, B.T., Sidibé, B.Y., Kanté, L., Diakité, I., Togo, A. and Diallo, G. (2019) Complications Per and Post Operatory (CPPO) at the Gabriel Toure University Hospital in Bamako. Surgical Science, 10, 287-296. https://doi.org/10.4236/ss.2019.108031

Received: June 7, 2019

Accepted: August 16, 2019

Published: August 19, 2019

Copyright $\odot 2019$ by author(s) and Scientific Research Publishing Inc. This work is licensed under the Creative Commons Attribution International License (CC BY 4.0).

http://creativecommons.org/licenses/by/4.0/

\begin{abstract}
Introduction: Despite the use of less invasive and increasingly effective techniques in order to reduce the morbi-mortality per and post-operative, the CPPO remain an important problem in surgery. Objectives: To determine the rate of per and post-operative complications, to describe the types of complications and to identify their risk factors. Methodology: This was a prospective study carried out from 04 April to 03 June 2016 in the surgical department of CHU-Gabriel TOURE. All patients aged 18 and over operated in the Surgical Department (General Surgery, Gynaecology and Obstetrics, Urology, Traumatology, Otolaryngology, Neurosurgery and Emergency Department), having been hospitalized at least for 24 hours after surgery, were retained. The method of sampling $N=P(1-P) Z \alpha^{2} / I^{2}$ was used; the minimum size necessary was 209 patients. We conducted invitations and the phone call to determine the occurrence of complications and survival of patients up to 30 days after surgery. Results: We counted 262 patients, of whom $142(54.2 \%)$ were women and $120(45.8 \%)$ were men with a sex ratio $=0.85$. The average age was 41.48 years, with extremes of 18 and 86 years. We found 71 complications in 61 patients, an early CPPO rate of $23.28 \%$. The various complications encountered were: urinary tract infections (26.76\%), surgical site infections $(28.17 \%)$, pulmonary infections (12.68\%) and Deaths $(21.13 \%)$. The occurrence of complications prolonged the hospital stay by 6 days and increased the average cost of care of 102,700 FCFA. According to Clavien Dindo's classification, the severe postoperative complication in our series was 9.16\% (grade III + IV + V). Factors favoring the occurrence of CPPO were age $>41$ years old, ASA $>$ II, the classes of Altemeier 3 and 4, NNISS score 1 and 2, diabetes and hemoglobin rate $8 \mathrm{~g} / \mathrm{dl}$. Conclusion: Complications per
\end{abstract}


and post-operative (CPPO) are common in the department of Surgery of CHU-Gabriel TOURE and are dominated by post-operative infection. These complications seem to be favored by multiple factors more related to the patients than to the hospital structure.

\section{Keywords}

Post-Operative Complications, Surgery

\section{Introduction}

The complications per and post-operative (CPPO) indicate all the incidents or the accidents which can arise during or after any surgical operation. They are premature when they arise in 30 days after the intervention [1].

The population operated for surgery not-heart patient represents a major problem of public health, with approximately 234 million surgical procedures realized in the world annually [2]. Globally, in non-cardiac surgery, the brought back (reported) premature mortality varies from $2 \%$ to $4 \%$ [3] [4], with annual mortality from 5 to 10 million people.

In spite of the use of the less and less invasive and more and more successful techniques to reduce the morbi-mortality post-operative, the CPPO remain a major problem of public health.

In Africa: in Morocco, Zambudio A. [5] found a post-operative morbidity of $21 \%$ after 301 thyroidectomies. In the South of Sahara the CPPO are dominated by the infections post-operative, so DEM HAS [6] in Senegal and Mehinto [7] in Benin reported in 2001 the respective rates of complications of $11.6 \%$ and $20.9 \%$ after appendectomy and intervention of Wertheim.

In Mali, a rate of post-operative complication of $15.4 \%$ with $6.94 \%$ of infection and post-operative $2.4 \%$ of mortality is found by Traore A. [8]. In front of the rarity of works concerning the complications per and post-operative in Mali, we realized this work with the following objectives.

\section{Objectives}

It was to: Determine the frequency of the complications per and post-operative, describe the types of complications, identify risk factors for complications, and assess the cost of payment.

\section{Methodology}

This was a prospective analytical study that took place from 04 April to 03 June 2016, a period of 2 months. It involved 262 patients. Our study was carried out in the departments of the Department of Surgery of CHU-Gabriel TOURE. The various services concerned were: general surgery, obstetric gynecology, trauma, urology, oto-rhino-laryngology and neurosurgery. 


\subsection{Population}

It represented all patients admitted and operated in the various services mentioned during the study period.

\subsection{Sampling}

A similar study was conducted in 2006 in our department and found a complication rate of $15.44 \%$ [8].

The following formula was used to determine the required minimum

$$
N=P(1-P) Z \alpha^{2} / I^{2}
$$

$P=$ frequency of post-operative complications obtained previously.

$$
\begin{gathered}
Z \alpha=1.96 \\
I=\text { the risk of error }
\end{gathered}
$$

Thus for $p=0.1544$ and $I=0.05$ the sample size $N$ will be equal to 209 individuals. We continued to recruit up to 262 subjects who formed our sample for this study.

\subsection{Criteria for Inclusion}

Patients who were at least 18 years old, admitted and operated in the participating services and who performed at least one night of hospital stay after surgery were included in this study. The statistical test used was the chi ${ }^{2}$ test with a threshold of significance $\mathrm{P}=0.05$.

\subsection{Criteria for Non Inclusion}

Patients under 18 years of age;

Patient with less than one night in hospital;

Patients with incomplete records.

\subsection{Statistical Analysis}

The data were analyzed with epi-info software 7, the test used was the $\mathrm{Chi}^{2}$ test with a significance threshold $\mathrm{P} \leq 0.05$.

\subsection{Ethics}

The local Ethics Committee gave its approval for the completion of this study, and instructed us to inform the included patients.

All included patients were informed; they agreed to participate in the realization of this study by remaining anonymous.

\section{Results}

\subsection{Sociodemographic Data}

We admitted and operated 262 patients in two months that is 150 patients (57, $25 \%)$ in settled surgery and 112 patients (42.75\%) as a matter of urgency. The 
average age was $41.48 \pm 18.45$ years old with extremes of 18 and 86 years old. The men represented $45.8 \%$ and the women $54.2 \%$ with a sex ratio of 0.85 .

\subsection{Complications}

We found 71 complications at 61 patients or a rate of premature CPPO of $23.28 \%, 4$ patients presented complications per operating, that is $1.53 \%, 15$ cases of these complications evolved towards the death or $5.73 \%$. The rate of complication by service is summarized in Table 1 .

The lung infection was found at $3.44 \%$ (9/262) of the patients. It was frequent in neurosurgery, that is $13.33 \%(2 / 15)$ of the patients.

The pulmonary embolism was noticed in two services: the general surgery and the gyneco-obstetrics, they presented respectively $6.02 \%(5 / 83)$ and $1.18 \%(1 / 85)$. Her frequency in the population of study is $2.29 \%(6 / 262)$.

The mortality was $5.73 \%$ in the first 30 days post-operatoire.

The pulmonary embolism was the most frequent cause of death in our study with $40 \%(6 / 15)$ followed by the toxic shock with $33.33 \%(5 / 15)$ the causes of death are summarized in Table 2.

We recorded more deaths among emergency patients, $9.82 \%$ of patients $(11 / 112)$ versus $2.67 \%(4 / 150)$ in patients operating in scheduled surgery, $\mathrm{P}=$ $0.01, \mathrm{RR}=3.68 \mathrm{IC}:[1]-[11]$.

In the classification of Clavien Dindo, Grade II was the most common grade of $47.89 \%$. This classification of patients is summarized in Table 3.

Infection at the operative site was the most common complication with $28.17 \%(20 / 71)$, followed by urinary tract infection at $26.76 \%(19 / 71)$. The types

Table 1. Complications according to the services.

\begin{tabular}{ccc}
\hline Services of hospitalizations & Number of patients & Number of complication (\%) \\
\hline General surgery & 83 & $26(31.33)$ \\
Gynecology obstetrics & 85 & $15(17.65)$ \\
Traumatology & 23 & $4(17.40)$ \\
Urology & 44 & $10(22.73)$ \\
Neurosurgery & 15 & $5(33.33)$ \\
ORL & 12 & $1(8.33)$ \\
Total & 262 & $61(23.66)$ \\
\hline
\end{tabular}

Table 2. Cause of death.

\begin{tabular}{cc}
\hline Complications & Actual Death (\%) \\
\hline Cardiac arrest peroperatoire & $3(20)$ \\
Hemorrhagic shock & $1(6.67)$ \\
Toxic shock & $5(33.33)$ \\
Pulmonary embolism & $6(40)$ \\
TOTAL & $15(100)$ \\
\hline
\end{tabular}


Table 3. Classification of the complications according to Clavien Dindon.

\begin{tabular}{ccc}
\hline Classification of Clavien Dindon & Actual & Percentage \\
\hline Grade I & 13 & 18.31 \\
Grade II & 34 & 47.89 \\
Grade III a & 2 & 2.82 \\
Grade III b & 7 & 9.86 \\
Grade V & 15 & 21.13 \\
Total & 71 & 100
\end{tabular}

Table 4. The types (chaps) of complication.

\begin{tabular}{cccc}
\hline Types(Chaps) of complications & Actual & Percentage \\
\hline & Infected operating site & 20 & 28.17 \\
Infectious complications & Urinary Infections & 19 & 26.76 \\
& Lung Infections & 9 & 12.68 \\
Bleeding & & 2 & 02.82 \\
Pulmonary embolism & 6 & 08.45 \\
Death & 15 & 21.13 \\
Total & 71 & 100 \\
\hline
\end{tabular}

of complication are summarized in Table 4. Cardiac arrest in per operation was observed in $1.53 \%$ of patients.

\subsection{Risk Factors}

Complications were $32.11 \%$ (35/109) in patients who were $>41$ years old and $16.99 \%(26 / 153)$ for those who were 41 years of age with $\mathrm{p}=0.004, \mathrm{RR}=1.89$, CI: [1.21 - 2.95].

In the population of patients undergoing emergency surgery, $24.11 \%$ of patients $(27 / 112)$ had complications compared to $22.67 \%$ of patients $(34 / 150)$ in the population of patients undergoing surgery with a $\mathrm{P}=0.78$, emergency was not a risk factor in our study.

Complications were $71.43 \%(10 / 14)$ in patients classified as ASA III and IV and $20.56 \%(51 / 248)$ in patients classified as ASA I and II, representing a P = $0.00001 \mathrm{RR}=3.47, \mathrm{CI}:[2.3-5.24]$.

We found $83.33 \%$ (5/6) of diabetes-related complications compared to $21.88 \%$ (56/256) for non-diabetics with a $\mathrm{P}=0.0004, \mathrm{RR}=3.81 \mathrm{IC}$ : [2.49 - 5.83].

Complications were $47.06 \%(8 / 17)$ in patients with hemoglobin $8 \mathrm{~g} / \mathrm{dl}$ and $21.63 \%(53 / 245)$ in patients with hemoglobin $>8 \mathrm{~g} / \mathrm{dl}$.

Classes III and IV of Altmeier had 45.61\% (26/57) of complication compared to $17.07 \%(35 / 205)$ for Classes I and II, P $=0.00001 \mathrm{RR}=2.67$ IC: [1.76 - 4.04].

Thirty-three patients $(41.25 \%)$ in the NNISS I and II classes had complications and 28 patients $(15.38 \%)$ in class 0 had complications, one $\mathrm{P}=0.000009$ $\mathrm{RR}=2.68 \mathrm{IC}:[1.75-4.12]$ Table 5 . 
Table 5. Risk factors.

\begin{tabular}{ccccccc}
\hline \multirow{2}{*}{ Risk factors } & & \multicolumn{2}{c}{ With complication } & \multicolumn{2}{c}{ Without complication } & \multirow{2}{*}{ Statistical Test } \\
\cline { 3 - 6 } Age & $>41$ & 35 & 32.11 & 74 & 67.89 & $\mathrm{P}=0.004$ \\
& $\leq 41$ & 26 & 16.99 & 127 & 83.01 & $\mathrm{RR}=1.89$ \\
\multirow{2}{*}{ ASA } & III + IV & 10 & 71.43 & 4 & 28.57 & $\mathrm{P}=0.00001$ \\
& I + II & 51 & 20.56 & 197 & 79.44 & $\mathrm{RR}=3.47$ \\
\multirow{2}{*}{ Diabetes } & Yes & 5 & 83.33 & 1 & 16.67 & $\mathrm{P}=0.0004$ \\
& Not & 56 & 21.88 & 200 & 78.13 & $\mathrm{RR}=3.81$ \\
Cough Hb $\leq 8$ g/dl & $\leq 8$ & 8 & 47.06 & 9 & 52.94 & $\mathrm{P}=0.02$ \\
& $>8$ & 53 & 21.63 & 192 & 78.37 & $\mathrm{RR}=2.18$ \\
& IV-III & 26 & 45.61 & 31 & 54.39 & $\mathrm{P}=0.0001$ \\
ALTEMEIER & II-I & 35 & 17.07 & 170 & 82.93 & $\mathrm{RR}=2.67$ \\
\hline
\end{tabular}

General anaesthesia accounted for 53.44\% (140/262) of which $32.86 \%(46 / 140)$ had complications and complications after spinal anaesthesia represented $13.54 \%$ (13/96). In the major surgical operation population, $34.43 \%$ of patients had complications.

\subsection{Consequences of the Following}

Without complications the average cost of care was 186,200 FCFA with extremes of 9500 FCFA and 1,043,960 FCFA, standard deviation 176,484,448 FCFA. With complications this cost was 288,900 FCFA with extremes of 0 and 1,146,940 FCFA standard deviation $=244,233,365$ FCFA or a $\mathrm{P}=0.0004$.

With complications the average length of stay was 10.8 days with extremes of 1 and 54 days or a standard deviation of 11.3. Without complications the average length of stay was 5 days with extremes of 1 and 58 or a standard deviation of 4.87. $\mathrm{P}=0.0001$

\section{Comments and Discussion}

In this prospective study, which was the first in our hospital, we found 262 patients in 6 departments of the Department of Surgery at Gabriel TOURE Hospital. These included general surgery, obstetric gynecology, urology, trauma, neurosurgery, and oto-rhino laryngology.

\subsection{Rate of Complications}

Despite the use of less invasive and increasingly effective techniques to reduce per and post-operative mortality, the CPPO remain a major problem in surgery [10]. We found a frequency of $27.10 \%$ of CPPO, this result does not differ from that reported by $\mathrm{Li}$ in China [11] who found $39.3 \%, \mathrm{P}=0.17$.

It is lower than those found by pontes in Brazil and Coccolini in Italy [12] [13] which found $56.15 \%$ and $49.50 \%$ respectively with $\mathrm{P} \leq 0.05$. This difference 
would be related to the fact that their studies were based solely on major surgery.

However, our result is higher than those reported by Sylla in Mali and Tonye in Cameroon [14] [15] who found $22.4 \%$ and $14.3 \%$. This difference could be explained by some aspects in our study: heavy surgery cases (tumour conditions), multiple risk factors and the definition of post-operative complications in mild, moderate and severe.

\subsection{Morbidity}

Morbidity in our study is $23.28 \%$; this result does not differ statistically from Sylla $(18.52 \%)$ with a $\mathrm{P}=0.15$. It is higher than that reported by Tonye [15]. This difference can be explained by: the comorbidities of our patients, inclusion of major surgical cases in our study, expanded definition of complications (mild, moderate and severe).

The rate of infection at the operative site ranged from $6.8 \%$ to $26 \%$ with predominance in general surgery [16]. There is no statistically significant difference between our results and those of Tonye, Sylla and Askarian [12] [15] and [17]. According to the classification of Clavien Dindo, the severe postoperative complication in our series was $9.16 \%$ (grade III + IV + V). This result is similar to those reported by some authors: Li et al. en chine and Cerruto et al. in Italy [11] [18] who found $0.5 \%$ and $0.7 \%$ respectively with a $\mathrm{P} \leq 0.05$. However, it is higher than that found by Xiao et al. in China [19], which reported $3.26 \%$ or a $\mathrm{P}=$ 0.002 . This difference could be explained by the lack of diagnostic means for post-operative complications and the delay in their management.

\subsection{Mortality}

The gross mortality data found between countries vary between $1 \%-21 \%$ [3]. We found the same results as Pearse in Europe and Sylla in Mali [3] [12] which reported $4 \%$ and $5.17 \%$ respectively. As our structure is an emergency hospital, $9.82 \%(11 / 112)$ of emergency patients died compared to $2.67 \%(4 / 150)$ of patients in scheduled surgery, $\mathrm{P}=0.01, \mathrm{RR}=3.68 \mathrm{IC}$ : [1.2 - 11.3].

\subsection{Risk Factors}

Higher age $>41$ is considered to be a factor in the occurrence of periodic and post-operative complications. Complications represented $32.11 \%(35 / 109)$ in patients who were $>41$ years of age and $16.99 \%(26 / 153)$ for those who were 41 years of age with $\mathrm{P}=0.004, \mathrm{RR}=1.89, \mathrm{CI}$ : [9] [20]. Many African authors have found age to be a factor in the occurrence of periodic and post-operative complications [14] [21].

The urgency is considered by many authors as factor risks of arisen the complications per and post-operatoire. In our study, $24.11 \%$ (27/112) of the patients operated as a matter of urgency presented complications against $22.67 \%(34 / 150)$ of the patients operated in surgery settled with $\mathrm{P}=0.78$. So this study does not allow us to say that the urgency would be a favoring factor the arisen of the CPPO. 
The class ASA was quoted by several authors as influencing factor the arisen of CPPO [3] [12] [17] [19], our study allowed to find the same result with $71.43 \%$ of CPPO at the patients ASA $3+4$ against $20.97 \%$ at ASA $1+2(\mathrm{p}=$ $0.00001)$. Pignaton $W$ and al [22] in Brazil found that $98 \%$ of the perioperative deaths were in the classes ASA III and IV.

We found $83.33 \% 5 / 6$ ) of the complications bound to the diabetes against $21.88 \%(56 / 256)$ for the not diabetics with a $\mathrm{P}=0.0004, \mathrm{RR}=3.81$ IC: [2.49 5.83].

The complications represented $47.06 \% 8 / 17$ ) at the patients having a rate of haemoglobin $=8 \mathrm{~g} / \mathrm{dl}$ and $21.63 \% 53 / 245)$ at the patients having a rate of haemoglobin $>8 \mathrm{~g} / \mathrm{dl}$.

Razafindraibe and al [23] in Madagascar reported that the anaemia is associated with a significant risk of mortality.

The classes III and IV of Altmeier registered 45.61\% (26/57) of complication against $17.07 \%(35 / 205)$ for the classes I and II are $\mathrm{P}=0.00001, \mathrm{RR}=2.67 \mathrm{IC}$ : [1.76 - 4.04].

Our result is similar to that of Traore and al in Mali who found for Altmeier I and II 8.9\% of CPPO (37/417) versus 42.6\% CPPO (43/101) for Altmeier III and IV.

Tonye and al in Cameroon found that $70 \%$ of the patients being in the classes III and IV of Altemeir presented complications.

\subsection{Consequences}

The patients presenting CPPO have a duration of long hospitalization that those who did not present CPPO. The duration of long hospitalization in touch with the arisen of CPPO were approximately 10.77 days in our study; it was found in other series and would give some explanation by the coverage of certain complications. The complications comment operating increased the cost of the coverage of the order of 55.16\% (288,900 FCFA/186,200 FCFA). This additional cost bound to the CPPO was revealed by other authors [2] [4] [8].

\section{Conclusion}

The CPPO are frequent in the services of surgery of the CHU-GABRIEL TOURE and are dominated by the post-operative infection. They are at the origin of the increase of the hospital stay as well as the cost of the covering. The risk factors are multiple, a good organization of our structures of health, the respect for the standards and procedures and the control of the comorbidity will allow us to significantly decrease the frequency of the CPPO.

\section{Conflicts of Interest}

The authors declare no conflicts of interest regarding the publication of this paper.

\section{References}

[1] Tarsicio, U.L., Joshua, J., Lydia, M., Rui, F., Micaela, M.E., Atul, A.G., et al. (2016) 
Variability in Mortality Following Caesarean Delivery, Appendectomy, and Groin Hernia Repair in Low-Income and Middle-Income Countries: A Systematic Review and Analysis of Published Data. The Lancet, 4, E165-E174. https://doi.org/10.1016/S2214-109X(15)00320-4

[2] Weiser, T.G., Regenbogen, S.E., Thompson, K.D., Haynes, A.B., Lipsitz, S.R., Berry, W.R., et al. (2008) An Estimation of the Global Volume of Surgery: À Modelling Strategy Based on Available Data. The Lancet, 372, 139-144. https://doi.org/10.1016/S0140-6736(08)60878-8

[3] Pearse, R.M., Moreno, R.P., Bauer, P., Pelosi, P., Metnitz, P., Spies, C., et al. (2012) Mortality after Surgery in Europe: A 7 Day Cohort Study. The Lancet, 380, 1059-1065. https://doi.org/10.1016/S0140-6736(12)61148-9

[4] Chao, T.E., Sharma, K., Mandigo, M., Hagander, L., Resch, S.C., Weiser, T.G., et al. (2014) Cost-Effectiveness of Surgery and Its Policy Implications for Global Health: À Systematic Review and Analysis. The Lancet Global Health, 2, E334-E345. https://doi.org/10.1016/S2214-109X(14)70213-X

[5] Zambudio, A., Rodriguez, J., Soria, T., Canteras, M. and Parrilla, P. (2004) Prospective Study of Postoperative Complications after Total Thyroidectomy for Multynodular Goiters by Surgeons with Experience in Endocrine Surgery. Annals of Surgery, 240, 18-25. https://doi.org/10.1097/01.sla.0000129357.58265.3c

[6] Dem, A., Kasse, A.A., Diop, M., Fall, M.C., Diop, P.S., Dotou, C., et al. (2001) Colpohystérectomies élargies avec lymphadénectomies pour cancer du col utérin à l'institut du cancer de Dakar: À propos de 412 cas. Dakar Médical, 46, 39-42.

[7] Mehinto, D.K.I., Olory-Togbe, J.L.I. and Padonou, N.I. (2004) Les complications d'appendicectomie pour appendicite aigue chez l'adulte au Centre National Hospitalier et Universitaire (CNHU) de Cotonou. Médecine d Afrique Noire, 51, 361-365.

[8] Traoré, A., Diakité, I., Dembélé, B.T., Togo, A., Kanté, L., Coulibaly, Y., et al. (2011) Complications post opératoires en chirurgie abdominale au CHU Gabriel Touré Bamako. Médecine d Afrique Noire, 58, 31-35.

[9] Thierry, A. (2018) Statistique et epidemiologie: 100 exercices corrigés étudiants et professionnels en sciences de la santé. Maloine, Paris, 42.

[10] Biccard, B.M., Madiba, T.E., Pearse, R.M., Alexandris, P., Bhagwandass, D.R., Boffard, K.D., et al. (2015) The South African Surgical Outcomes Study: A 7 Day Prospective Observational Cohort Study. South African Medical Journal, 105, 465-475. https://doi.org/10.7196/SAMJ.9435

[11] Li, P., Lai, Y., Zhou, K. and Che, G. (2017) Analysis of Postoperative Complications and Risk Factor of Patients with Lung Cancer through Clavien-Dindon Classification. Chinese Journal of Lung Cancer, 20, 264-271.

[12] Pontes, S., Salazar, R.M., Torres, O.J.M. and Ma, T.C.B.C. (2013) Perioperative Assessment of the Patients in Intensive Care Perioperative Assessment of the Patients in Intensive Care Unit. Revista do Colégio Brasileiro de Cirurgióes, 40, 92-97. https://doi.org/10.1590/S0100-69912013000200002

[13] Coccolini, F., Montori, G., Ceresali, M., Calina, F., Iratury, F., Sugrue, M., et al. (2017) IROA: International Register of Open Abdomen, Preliminary Results. World Journal of Emergency Surgery, 12, 10. https://doi.org/10.1186/s13017-017-0123-8

[14] Sylla, A. (2012) Complications postopératoires dans le service de chirurgie de l'hôpital Fousseyni Daou de Kayes. Thèse de Medicine, des Techniques et des Technologies de Bamako, Bamako.

[15] Tonye, T.A., Essi, M.J., Handy, E.D., Ankouane, A., Minka Ngom, E., Ngo Nonga, 
B., et al. (2015) Complications postopératoires précoces dans les hôpitaux de district de la ville de Yaoudé. Human Health and Disease, 16.

[16] Ngaroua, J.E.N., Thomas, B. and Yaouba, D. (2016) Incidence des infections du site opératoire en Afrique sub-saharienne: Revue systématique et méta-analyse. The Pan African Medical Journal, 24, 171. https://doi.org/10.11604/pamj.2016.24.171.9754

[17] Askarian, M., Kouchak, F. and Palennik, C.J. (2011) Effect of Surgical Safety Check-Lists on Postoperative Morbidity and Mortality Rates, Shiraz, Faghihy Hospital, a 1-Year Study. Quality Management in Health Care, 20, 293-297. https://doi.org/10.1097/QMH.0b013e318231357c

[18] Cerruto, M.A., D’Elia, C., Piccoli, M., Cacciamani, G., Corsi, P., Artibani, W., et al. (2016) Association between Postoperative Thromboembolism Prophylaxies and Complications Following Urological Surgery. Experimental and Therapeutic Medicine, 11, 157-163. https://doi.org/10.3892/etm.2015.2845

[19] Xiao, H., Pan, S.G., Yin, B., Luo, W., Quan, H., Qiu, X.X., et al. (2013) Clavien-Dindon Classification and Risk Factor for Complications after Radical Gastrectomy for Gastric Cancer. National Medical Journal of China, 93, 3667-3670.

[20] Mariette, C., Alves, A., Benoist, S., Bretagnol, F., Mabrut, J.Y. and Slim, K. (2005) Soins péri opératoires en chirurgie digestive. Recommandations de la Société Française de Chirurgie Digestive (SFCD). Annales de chirurgie, 130, 108-124. https://doi.org/10.1016/j.anchir.2004.12.003

[21] Anoumou, M., Koume, M., Guedgbe, F. and Varango, G. (2000) Etude des infections post opératoires en chirurgie orthopédique et traumatologique de Treisheville. Revue africaine de chirurgie, 4, 242.

[22] Pignaton, W., Braz, J.R.C., Kusano, P.S., Módolo, M.P. and de Carvalho, L.R. (2016) Perioperative and Anesthesia-Related Mortality: An 8-Year Observational Survey From a Tertiary Teaching Hospital. Medecine, 95, e2208. https://doi.org/10.1097/MD.0000000000002208

[23] Razafindraibe, F.A.P., Randrianambinina, T.P., Velomora, A., Rakotomavo, F.A. and Rakotoarison, R.C.N. (2016) Facteurs de mortalité des urgences chirurgicales. Revue Tropicale de Chirurgie, 10, 23-26. 